Foro Interno. Anuario de Teoría Política

ISSN: 1578-4576

\title{
Cinco siglos de un debate: rebelión y reforma frente a revolución en las Comunidades de Castilla en su V Centenario
}

\author{
Salvador Rus Rufino ${ }^{1}$; Eduardo Fernández García ${ }^{2}$
}

Recibido: 19 de agosto de 2020 / Aceptado: 28 de septiembre de 2020

Resumen. Las Comunidades de Castilla, como movimiento social y político, pueden caracterizarse como una tentativa de renovación de la monarquía carolina como forma de gobierno. El creciente conocimiento sobre la circulación de ideas políticas que informaron el corpus doctrinal comunero permite precisar conceptual y terminológicamente un debate revisitado con frecuencia sobre la naturaleza revolucionaria o no de tal proceso. Acudir a los textos de los principales sustentadores teóricos de las Comunidades, tanto como a los documentos de sus reivindicaciones, y no solo a una interpretación de síntesis ex post, contribuye a perfilar el alcance sobre sus pretensiones de reforma respecto a la forma del Estado o a la forma del gobierno, sobre la base de la participación y la igualdad. Apoyarse en las nociones de régimen político y sistema político a la luz de tales textos permite una mejor comprensión del movimiento como reformista más que como revolucionario.

Palabras clave: Comunidad; igualdad; participación; representación; revolución; monarquía carolina.

[en] Five Centuries of Debate: Rebellion and Reform rather than Revolution in the Communities of Castile

Abstract. The Communities of Castile, as a social and political movement, have been characterized as an attempt to renew Charles V's reign as a form of government. The growing body of knowledge on the political ideas that informed the doctrinal corpus of the Communities shed light conceptually and terminologically on the frequently revisited debate regarding the revolutionary nature of that movement. Using texts from the main theoretical supporters of the Communities as well as documentation establishing their claims, this paper outlines the scope of their demands for reform of the State or form of government, based on participation and equality. Relying not only on ex post interpretations or syntheses, but on the very notions of political regime and political system in the original texts, one may reach a better understanding of the movement as a reformist rather than a revolutionary process.

Keywords: Community; equality; participation; representation; revolution; Charles V's monarchy.

Sumario: 1. La consideración de los comuneros como revolución en el siglo diecinueve. 2. Los comuneros y la monarquía como forma de Estado y de gobierno. 3. ¿Revuelta, movimiento social o revolución? 4. Conclusiones. 5. Referencias bibliográficas.

Cómo citar: Salvador Rus Rufino y Eduardo Fernández García, “Cinco siglos de un debate: rebelión y reforma frente a revolución en las Comunidades de Castilla en su V Centenario”: Foro Interno. Anuario de Teoría Política, vol. 21 (2021), pp. 3-16.

El 23 de enero de 1521 se libró la batalla de Villalar. En ella se enfrentaron los ejércitos del Emperador Carlos V (1500-1558), que ya era rey de España, apoyado por las huestes de los nobles, y el de las Comunidades. El resultado fue el aplastamiento del contingente comunero frente a las tropas imperiales. Este hecho supuso el final del movimiento social y político que alteró durante aproximadamente un año la vida política en Castilla. En estos meses un grupo de ciudades y de súbditos del rey vieron que era necesario llevar a cabo una reforma de gran calado en la forma de Estado y de gobierno monárquica. El tiempo les dio la razón y siglos después otros consiguieron realizar lo que ellos anticiparon.

Desde el siglo dieciséis hasta nuestros días los españoles se han formado diferentes opiniones sobre las Comunidades y los comuneros. Los juicios son discrepantes y en muchos casos contradictorios. Este hecho muestra que el movimiento ha dejado huella en la Historia de España y en la memoria de los españoles.

\footnotetext{
Universidad de León (España)

E-mail: srusr@unileon.es

2 Universidad de León (España)

E-mail: eduardofernandez@institutio.es

Foro interno 21 (2021): 3-16
} 
En este trabajo recogeremos sólo el parecer de diferentes autores sobre el movimiento comunero que lo calificaron como una revolución. Trataremos las ideas de los comuneros sobre la monarquía como forma de Estado y de gobierno ${ }^{3}$. Y se dará una respuesta a la pregunta que se plantea en el título, si los comuneros quisieron llevar a cabo una revolución o fue rebelión de las ciudades.

\section{La consideración de los comuneros como revolución en el siglo diecinueve}

Durante quinientos años se ha investigado, estudiado, escrito y tratado de explicar y de comprender las causas y las consecuencias de este movimiento social. Se puede afirmar que cada generación de españoles ha tenido una valoración y ofrecido a la siguiente una interpretación de las Comunidades, que se ha plasmado en publicaciones y en manifestaciones artísticas. La valoración de la historiografía sobre los comuneros no ha sido ni es unánime 4 . Desde muy pronto este hecho histórico dividió a los historiadores durante cinco siglos. En estos quinientos años ninguna generación ha mostrado indiferencia ante los hechos sucedidos durante la revuelta de las Comunidades. Encontramos a lo largo de este tiempo críticos implacables, descalificaciones globales, censuras a las propuestas y propósitos, pero igualmente alabanzas, justificaciones y una defensa del valor, el arrojo y la audacia de unos hombres y mujeres que trataron de cambiar una sociedad y una forma de gobernarla.

Las palabras de Fray Antonio de Guevara (1480-1545) pueden servir para introducir la cuestión que nos ocupa en este artículo. En una de sus famosas cartas escribió que "lo que pedían los plebeyos de la República es a saber, que en Castilla todos contribuyessen, todos fuessen iguales, todos pechassen y que a la manera de Señorias de Italia, se governassen, lo qual es escandalo oirlo, y blasfemia dezirlo"s. Esta valoración realizada por un personaje cercano a Carlos $\mathrm{I}^{6}$ muestra que los comuneros fueron considerados unos plebeyos que pretendieron renovar y cambiar toda la sociedad de su tiempo y transformar la economía. Estas innovaciones, pese a lo que pensaran los partidarios del emperador, no negaron nunca la legitimidad y la autoridad del rey, ni trataron de sustituir al monarca por un órgano de gobierno colegiado como fue la Santa Junta, tal como han afirmado algunos autores ${ }^{7}$, como se verá más adelante.

El problema de la consideración o no de las Comunidades como una revolución tiene su origen en los primeros años del siglo diecinueve. El liberalismo y otras tendencias políticas plantearon cambios profundos en la forma de gobierno, en las leyes y en la sociedad de las monarquías europeas. Los políticos e intelectuales españoles y alguno europeo mostraron a los comuneros como un ejemplo y un antecedente de sus ideas, ideales y proyectos de reforma social y política. Entre los muchos autores que hacen referencia a este movimiento, vamos a citar sólo algunos. Agustín J. Argüelles Álvarez (1776-1844) en el discurso preliminar de la Constitución de 1812 de las Cortes de Cádiz, afirmó que:

...la Constitución de Castilla es admirable y digna de todo respeto y veneración. Por ella se le prohibía al Rey partir el señorío; no podía tomar a nadie su propiedad; no podía prenderse a ningún ciudadano dando fiador; por fuero antiguo de España, la sentencia dada contra uno por mandato del Rey era nula; el Rey no podía tomar de los pueblos contribuciones, tributos ni pedidos sin el otorgamiento de la nación junta en Cortes, con la singularidad de que éstas no los decretaban hasta haber obtenido competente indemnización de los agravios deducidos en ellas, en lo cual la nación se había manifestado siempre tan celosa y sentida que más de una vez expresó el resentimiento que le causaba la repulsa con actos de violencia y enfurecimiento, como sucedió en los desastrosos movimientos de Segovia y demás ciudades de Castilla después de las Cortes de La Coruña, en

\footnotetext{
Muchas de las ideas sobre el rey y el proyecto dinástico están desarrolladas del artículo Salvador Rus Rufino, “"Quel Reyno no manda al Rey: y no el Rey al Reyno'. La legitimidad de Carlos I en el tiempo de las Comunidades de Castilla quinientos años después": Res publica. Revista de Historia de las Ideas Políticas, vol. 23, n. ${ }^{\circ} 2$ (2020), pp. 151-161.

4 Para ver unas síntesis completas de la historiografía sobre las Comunidades se puede consultar Joseph Pérez, "Pour une nouvelle interpretation des 'Comunidades' de Castilla": Bulletin Hispanique, tome 65, n. ${ }^{\circ}$ 3-4 (1963), pp. 238-283, también en Joseph Pérez, Los Comuneros, RBA, Barcelona, 2006, pp. 235-272; Mateo Ballester Rodríguez, "Comunidad, patria y nación como fuentes de la legitimidad política en las Comunidades de Castilla (1520-1521)": Revista de Estudios Políticos, n. 153 (2011), pp. 215-249; Juan Ignacio Gutiérrez Nieto, Las comunidades como movimiento antiseñorial, Planeta, Barcelona, 1973, pp. 21-122; Fernando Martínez Gil, "La memoria histórica de las comunidades en los siglos XVI y XVII", en Carlos I y su tiempo: actas del Congreso Beresit III, vol.3, Archivo Municipal de Toledo, Toledo, 2002, pp. 11-38; José J. Jerez Calderón, Pensamiento político y reforma institucional durante la guerra de las Comunidades de Castilla (1520-1521), Marcial Pons, Madrid, 2007, pp. 32-80; Enrique Berzal de la Rosa, Los comuneros. De la realidad al mito, Silex, Madrid, 2008, pp. 197-321; Ramón Sánchez González, "La Historiografía de las Comunidades”, en Miguel F. Gómez Vozmediano (coord.), Castilla en llamas. La Mancha comunera, Almud Ediciones, Ciudad Real, 2008, pp. 15-32.

Antonio de Guevara, Epistolas Familiares, primera parte, Casa Iacobo Meurcio, Anveres, 1633, p. 252.

6 Para el rey Carlos I de España y V de Alemania usaremos el ordinal correspondiente a rey de España, excepto cuando se haga referencia a él como emperador.

Antonio Cánovas del Castillo, "De las ideas políticas de los españoles durante la Casa de Austria (Apuntes críticos)": Revista de España, tomo IV, n. ${ }^{o} 16$ (1868), p. 520; José A. Maravall, Las comunidades de Castilla. Una primera revolución moderna, Alianza Editorial, Madrid, 1979, pp. 87-91 y 203 .
} 
que se concedieron al emperador Carlos V los subsidios que había pedido antes de haber satisfecho a las quejas que le presentaron los procuradores del reino ${ }^{8}$.

Esta idea expuesta con determinación y valentía en el último reducto que no logró ocupar el ejército francés, fue recogida y continuada por Francisco Martínez Marina (1754-1833) ${ }^{9}$ y Francisco Martínez de la Rosa $(1787-1862)^{10}$, que consideraron a los comuneros como unos héroes defensores de la libertad del pueblo.

Pasado el primer tercio del siglo diecinueve, el movimiento comunero se convirtió en el paradigma de la lucha contra el absolutismo de los monarcas ${ }^{11}$. El liberalismo vio en los comuneros los primeros adalides de la lucha por la libertad porque se oponían al poder constituido ${ }^{12}$. Villalar significó el hundimiento de las libertades del pueblo castellano y el sometimiento de Castilla a una política imperial que le era ajena. Fueron los héroes y los mártires de las libertades civiles que se sacrificaron por sus ideales. Sucumbieron ante la intransigencia de un grupo de colaboradores del rey Carlos I que aplastó por la fuerza sus justas reivindicaciones ${ }^{13}$. El movimiento de las Comunidades luchó por conseguir las libertades políticas de Castilla y para los castellanos. Otros autores, por ejemplo, Manuel Colmeiro y Penido (1818-1894) ${ }^{14}$, vieron a los comuneros como los abanderados de las libertades del pueblo, aquellos que pusieron límites al poder regio. En plena Revolución Gloriosa de 1868, Emilio Castelar y Ripoll (1832-1899), que fue presidente de la I República y brillante orador, en sus discursos calificó la revolución como una epopeya, una elegía de la libertad y una muestra de la resistencia al régimen monárquico absoluto ${ }^{15}$. Esta tendencia fue seguida por autores ligados al proyecto de renovación pedagógica de la Institución Libre de Enseñanza, como Joaquín Costa Martínez (1846-1911) ${ }^{16}$, Gumersindo J. de Azcárate Menéndez (1840-1917) ${ }^{17}$ y Vicente Santamaría de Paredes (1853-1924). Todos ellos calificaron a las Comunidades de Castilla como una de las grandes revoluciones históricas, que fracasó y fue derrotada por el absolutismo monárquico. Para una corriente historiográfica alemana de esta época el movimiento comunero fue un intento de establecer una democracia en Castilla ${ }^{18}$.

También hubo críticas a la interpretación del liberalismo. El movimiento regeneracionista, liderado por Ángel Ganivet García (1865-1898) ${ }^{19}$, Ricardo Macías Picavea (1846-1899)20 y Rafael Altamira y Crevea (1866-1955 $)^{21}$ consideró que los comuneros eran unos políticos apegados a una tradición que defendía un nacionalismo trasnochado, que se oponía a la política moderna, innovadora y europea de emperador Carlos $\mathrm{V}^{22}$. Marcelino Menéndez Pelayo (1856-1912) también participó de esta idea ${ }^{23}$. El contrapunto de esta interpretación y consideración de los comuneros lo encontramos en la reivindicación de este movimiento en autores tradicionalistas que defendían una democracia orgánica como Manuel de Bofarull y Romañá (18871974) ${ }^{24}$ y Juan Vázquez de Mella (1861-1928) ${ }^{25}$. A finales del siglo diecinueve el académico Manuel Danvila y

Agustín de Argüelles, Discurso preliminar a la Constitución de 1812, introducción de Luis Sánchez Agesta, Centro de Estudios Constitucionales, Madrid, 1981, p. 72.

Francisco Martínez Marina, Teoría de las Cortes o Grande Juntas nacionales de los reinos de León y Castilla: monumentos de su Constitución politica y de la soberanía del pueblo, con algunas observaciones sobre la Ley Fundamental de la monarquía española, sancionada por las Cortes generales y extraordinarias, y promulgada en Cádiz a 19 de marzo de 1812, Imprenta de Fermín Villalpando, Madrid, 1813, tres tomos.

10 Francisco Martínez de la Rosa, Bosquejo histórico de las Comunidades, en Obras Dramáticas, Espasa Calpe, Madrid, 1954, pp. 1-115.

11 Juan Romero Alpuente, Historia de la revolución española y otros escritos, Centro de Estudios Constitucionales, Madrid, 1989. Al mismo tiempo se publica la crónica de Pedro de Alcocer por: Henri Ternaux Compans, Les comuneros: d'après l'histoire inédite de Pedro de Alcocer, Paulin editeur, Paris, 1834.

12 Ángel Rivero Rodríguez, “El mito comunero y la identidad nacional española”, en Antonio Álvarez-Ossorio Alvariño y Bernardo J. García García (eds.), La Monarquía de las naciones. Patria, nación y naturaleza en la Monarquía de España, Fundación Carlos de Amberes, Madrid, 2004, pp. 724-737.

13 Algunos ejemplos podemos encontrar en las obras de autores como Jaime Balmes, El protestantismo en comparación con el catolicismo en sus relaciones con la civilización europea, en Obras Completas, vol. VIII, tomo IV, ed. de Ignacio Casanovas, Biblioteca Balmes, Barcelona, 1925, pp. 200-208; Antonio Ferrer del Río, Decadencia de España. Primera parte. Historia del Levantamiento de las Comunidades de Castilla 1520-1521, Establecimiento Tipográfico de Mellado, Madrid, 1850; Modesto Lafuente, Historia General de España, tomo XI, Establecimiento Tipográfico de Mellado, Madrid, 1858.

14 Manuel Colmeiro, De la Constitución y del Gobierno de los reinos de León y Castilla, Imprenta de J. Martín Alegría, Madrid, 1855. En este sentido cabe cita al historiador francés Victor Auguste Du Hamel, Historia constitucional de la Monarquía española: desde la invasión de los bárbaros hasta la muerte de Fernando VII (411-1833), Mellado Editor, Madrid 1848, dos volúmenes. Original en francés Victor Auguste Du Hamel, Histoire constitutionnelle de la monarchie espagnole, depuis l'invasion des hommes du Nord jusqu'à la mort de Ferdinand VII, 411-1833, Libraire D’Amyot, Paris, 1845.

5 Emilio Castelar, Discursos parlamentarios, Congreso de Diputados, Madrid, 2003.

6 Joaquín Costa, Historia crítica de la revolución española, ed. de A. Gil Novales, Centro de Estudios Constitucionales, Madrid, 1992.

Gumersindo de Azcárate, Minuta de un testamento (Ideario del krausismo liberal), ed. de José Luis Monereo, Editorial Comares, Granada, 2004.

18 Véase Konrad Häbler, "Zur Geschichte der kastilischen Comunidades. 1520-21": Historische Zeitschrift, vol. 95 (1905), pp. 385-434 y Ludwig Pfandl, Historia de la Literatura Nacional Española en la Edad de Oro, Editorial Gili, Barcelona, 1933 [original: Ludwig Pfandl, Geschichte der spanischen Nationalliteratur in ihrer Blütezeit, Freiburg im Breisgau, 1929].

9 Ángel Ganivet, Idearium español, Espasa-Calpe, Madrid 1990.

Ricardo Macías Picavea, El problema nacional, Librería General de Victoriano Suárez, Madrid, 1899.

Rafael Altamira, Historia de la civilización española, Manuel Soler, Barcelona, 1901.

22 Roberto López Vela, “Las Comunidades: ¿lucha por la libertad o feudalismo concejil? El debate sobre la 'revolución' en la historiografía de la Restauración”: Investigaciones Históricas: época moderna y contemporánea, n. 24 (2004), pp. 105-138.

23 Marcelino Menéndez Pelayo, Historia de los heterodoxos españoles, Biblioteca de Autores Cristianos, Madrid, 1965-1967, dos tomos.

24 Manuel de Bofarull y Romañá, Las antiguas Cortes. El moderno Parlamento. El régimen representativo orgánico, s.n., Madrid, 1912.

25 Juan Vázquez de Mella, Selección de elocuencia e historia, en Obras Completas, vol. I, Junta Nacional del Homenaje a Mella, Madrid, 1932. 
Collado (1830-1906) publicó una gran obra muy documentada con la que trató de reinterpretar el movimiento comunero en su justo medio con una multitud apabullante de datos y documentos no concluyó si fue una revolución o no ${ }^{26}$. Es significativo que Manuel Azaña Díaz (1880-1940), a propósito de un análisis de la obra de Ángel Ganivet, afirmara que los comuneros fueron unos libertadores que querían sacudirse el yugo aplastante del despotismo de Carlos I y de sus consejeros flamencos. Su derrota truncó un incipiente desarrollo constitucional en España ${ }^{27}$. Por su parte, Américo Castro Quesada (1885-1972) señaló que los Comuneros eran la muestra de un movimiento genuino de la aspiración castellana hacia la consecución de la libertad política y social. Puso de relieve la importancia de los conversos en el origen y el desarrollo del movimiento ${ }^{28}$.

La generación de profesores e investigadores de la segunda mitad del siglo veinte, consideraron a los Comuneros como unos adalides de la modernidad, porque este movimiento político y social, fue un intento de estructuración constitucional a escala nacional, que se enfrentó a la mentalidad de Carlos I y a su proyecto de establecer un imperio universal, provocando una guerra civil en Castilla ${ }^{29}$. El historiador Demetrio Ramos Pérez (1918-1999), demostró que la oposición de las Comunidades al rey Carlos I se debe a que al asumir el monarca la dignidad imperial del Sacro Imperio Romano Germánico, restaría fuerzas, medios y energías al desarrollo de lo que se podría llamar un imperio netamente castellano ${ }^{30}$.

Un impulso muy notable a la moderna investigación sobre las Comunidades lo dieron los estudios de los autores José Antonio Maravall Casesnoves (1911-1986), Joseph Pérez (1931-2020), Juan Ignacio Gutiérrez Nieto y Stephen Haliczer. Estos cuatro autores defendieron con distintos argumentos que las Comunidades constituyó un auténtico movimiento revolucionario.

José A. Maravall acentuó el carácter social, politológico y revolucionario de las Comunidades. La calificó como la primera revolución de los tiempos modernos porque trataron de formar un Estado constitucional antes que otras naciones como los EE.UU. y Francia ${ }^{31}$. Por su parte, el hispanista francés Joseph Pérez estudió los aspectos sociales y las consecuencias del movimiento comunero. Se inclinó también a considerarlo una revolución porque trató de cambiar a fondo la organización política y social de Castilla. En su obra calificó muchas de las actitudes y de las propuestas de los comuneros como una revolución: “... la revolución que en un principio era meramente política, provocaba ahora reivindicaciones sociales que ponían en cuestión las estructuras heredadas del pasado" 32 , es decir, la revolución comunera no se limitó a los aspectos políticos, fue una revolución de gran alcance que se propuso cambiar la sociedad y la estructura misma del reino de Castilla ${ }^{33}$. Gutiérrez Nieto profundizó en la consideración de las Comunidades como un movimiento social y político revolucionario con un marcado carácter antiseñorial ${ }^{34}$. Desde un punto de vista sociológico el norteamericano Haliczer mantuvo que los cambios sociales que se produjeron en Castilla desde la muerte de Isabel I (14511504) y la sucesivas regencias precipitaron la revuelta comunera ${ }^{35}$.

Quinientos años después, podemos y debemos realizar un nuevo balance de este movimiento social y político, que fue tan importante y decisivo para la configuración de una España moderna que entró con velas desplegadas en una nueva época en la que asumió el liderazgo mundial. Para los autores es necesario, tiene sentido y utilidad conocer el debate de las ideas políticas que se produjo entre mayo de 1520 y abril de 1521 , once meses decisivos en la Historia de España. Durante este tiempo se cuestionó el modelo de sociedad, la

26 Manuel Danvila y Collado, Historia crítica y documentada de las Comunidades de Castilla, Establecimiento Tipográfico de la viuda e hijos de M. Tello, Madrid, 1897-1899, seis tomos. El autor no supo extraer de los documentos todo el partido.

27 "Merced al suceso de Villalar, el devenir constitucional español tomó tal rumbo que, mirando al fondo de las cosas, no se ha rectificado todavía". Manuel Azaña, Plumas y palabras, Crítica, Barcelona, 1990, p. 54. En este sentido también se pronunció el historiador inglés Henry Latimer Seaver, The Great Revolt in Castile. A Study of the Comunero Movement of 1520-1521, Constable \& Company Limited, London, 1930.

28 Américo Castro, La Celestina como contienda literaria, Revista de Occidente, Madrid, 1965.

29 Enrique Tierno Galván, “Es el Lazarillo un libro comunero?”, en Escritos (1950-1960), Tecnos, Madrid, 1971; Enrique Tierno Galván, “De las Comunidades o la historia como proceso", en Escritos (1950-1960), Tecnos, Madrid, 1971.

30 Demetrio Ramos, Historia de las Cortes tradicionales de España, Aldecoa, Burgos, 1944. Esta es una cuestión poco debatida y escasamente analizada. Los castellanos en este tiempo sentían un orgullo por pertenecer a un reino que desde 1492 había conseguido importantes éxitos políticos. En el primer tercio del siglo dieciséis estaban inmersos en la consolidación de una monarquía universal que tenía posesiones en Europa, África y América. Se estaban realizando grandes proyectos y, con toda probabilidad, los castellanos sentían que el paralelo de la Historia pasaba por su reino, por España. Se puede formular una hipótesis. En el conflicto de las Comunidades se opusieron dos conceptos de monarquía universal y de imperio. Uno el castellano y otro el europeo. Uno el territorial y otro el marítimo. Desde este punto de vista, el movimiento de las Comunidades sería un choque de mentalidades.

31 Maravall, Las Comunidades de Castilla.

32 Pérez, La revolución de las Comunidades de Castilla (1520-1521), p. 261. El libro comienza con estas palabras: "La revolución que vamos a estudiar...", ibid., p. 9; en otros lugares afirmó que los actos, la actitud y las propuestas eran revolucionarias véase: ibid., pp. 109, 112, 117, 141, 158, $167,172,177,195,203,250,302$ y en otros lugares.

33 Joseph Pérez, "Pour une nouvelle interpretation des 'Comunidades' de Castilla", citado por Joseph Pérez, La revolución de las Comunidades de Castilla (1520-1521); Joseph Pérez, “Tradición e innovación en las Comunidades de Castilla”, en VV. AA., Hommage des hispanistes français à Noël Salomon, Editorial Laia, Barcelona, 1979 y Joseph Pérez, "Las Comunidades de Castilla. Nuevas Perspectivas", en Martínez Gil (ed.), En torno a las comunidades de Castilla: actas del Congreso Internacional "Poder, Conflicto y Revuelta en la España de Carlos I", Ediciones Universidad de Castilla-La Mancha, Toledo, 2002, pp. 133-146.

34 Gutiérrez Nieto, Las comunidades como movimiento antiseñorial.

35 Stephen Haliczer, The Comuneros of Castile. The Forcing of a Revolution (1475-1521), University of Wisconsin Press, Madison, 1981, existe traducción al español: Stephen Haliczer, Los Comuneros de Castilla. La forja de una revolución, 1475-1521, Ayuntamiento de Valladolid, Valladolid, 1986. 
forma de gobierno, y la organización política y territorial del reino de Castilla. Las ideas que se debatieron se anticiparon unos doscientos cincuenta de años a las revoluciones del último tercio del siglo dieciocho ${ }^{36}$.

\section{Los comuneros y la monarquía como forma de Estado y de gobierno}

Para afirmar si los comuneros fueron o no revolucionarios es imprescindible analizar su visión de la forma de Estado monárquica y de la figura del rey Carlos I. De esta manera podremos comprobar si pretendieron cambiar la forma de Estado o sólo una manera de entender el ejercicio del poder monárquico.

El rey se presentaba ante su pueblo como un gobernante que no tenía superior en todo su territorio, él era el cuerpo completo del reino, el garante de la paz, la justicia y del bienestar de los súbditos, el jefe del ejército y poseía una autoridad indiscutible desde el punto de vista legal y político. Su poder era omnímodo y personal porque controlaba los resortes jurídicos del Estado, los recursos económicos necesarios para gobernar y las instituciones que tenían que controlarle. Además, el rey estaba respaldado por una Corte y sus colaboradores de confianza en los que se apoyaba para llegar allá donde él no podía alcanzar.

Carlos I estaba convencido de que Castilla era una propiedad privada suya. Una parte de su cuantiosa y variada herencia. La fortuna se había aliado para que él, a la corta edad de dieciséis años, contara con territorios dispersos en varios lugares de Europa, en el norte de África, en algunos puntos del Mediterráneo y en América. Poco tiempo después de desembarcar en la Península fue elegido emperador del Sacro Imperio Romano Germánico, título que había ostentado su bisabuelo Federico III (1415-1493) y su abuelo Maximiliano I (1459-1519).

Para dilucidar si se produjo o no una revolución, es necesario abordar el debate sobre la monarquía como forma de gobierno y, en concreto, el proyecto político encarnado por Carlos I. La primera señal de discrepancia entre el rey y los comuneros se manifestó en las Cortes de Santiago y La Coruña. Los procuradores se sentían representantes de las ciudades con un mandato imperativo de ésta, por esta razón propusieron primero la aprobación de las peticiones de las ciudades y, después, una vez discutidas y aprobadas las demandas, se procedería a votar el servicio que solicitaba el rey. Este hecho revela que, de un lado, los procuradores no se consideraban unos títeres nombrados por el monarca; de otro, la unidad de acción y el compromiso con sus representados que mostraron en la sede de las Cortes significó que se reconocían como los auténticos representantes de la soberanía del reino y, por tanto, ellos eran los que constituían el reino a través de su mandato representativo. Su actitud se diferenciaba de la de los procuradores de otras épocas que más que representantes eran cómplices complacientes de los hechos ocurridos o de las exigencias del rey. Con esta actitud proclamaron su libertad de pensamiento y de actuación, su resistencia a las presiones del monarca y de sus estrechos colaboradores y, también, por último, su deseo vehemente de participar en el gobierno del reino ejerciendo un control sobre el poder del rey y de sus colaboradores.

En las relaciones entre el rey y las Comunidades nos encontramos dos concepciones del poder político enfrentadas. De un lado, la idea de propiedad sobre el reino de Carlos I se basaba en un concepto del poder político piramidal que se ejercía sobre una sociedad estamental y diferenciadora. La unidad política era dual, en un lado y en la cúspide de la pirámide, estaba el rey y, en otro, los demás estamentos sociales, nobleza, clero y pueblo. El deber u oficio de reinar exigía encontrar el equilibrio entre las dos partes. En cambio, los comuneros proclamaron que, en nombre de la libertad, el gobierno y la iniciativa política se encuentran en el pueblo, porque son ellos los que eligen a sus representantes que constituyen la totalidad del reino y los que transfieren o delegan en el poder al rey.

En las Cortes de Valladolid de 1518 se preparó el camino para que las Comunidades reivindicaran una relación diferente entre el monarca y el pueblo, se ha denominado "contrato callado" y que se expresó muy bien en una de las resoluciones, en las que se conminó al rey a que gobernara de forma justa, buscando el bien de todos los súbditos, respetando las leyes y las instituciones. Si no gobernaba de esa manera no puede titularse como rey, sino como un tirano ${ }^{37}$.

Los acuerdos deben cumplirse y no se pueden romper de manera unilateral por una de las partes que asume y lo firma ${ }^{38}$. En caso de ruptura o defección la parte afectada debe resistirse a los abusos de la parte que ha

Nos referimos al ciclo revolucionario de finales del siglo dieciocho, la que dio lugar a la independencia norteamericana de 1776 y la Revolución francesa de 1789. El trabajo clásico de Jacques Godechot, Les Révolutions 1770-1799, Presses Universitaires de France, Paris, 1965, es muy ilustrativo y una excelente introducción para conocer este período de revolucionario atlántico-europeo.

37 "Pues, muy poderoso sennor, sy esto es verdad, vuestra alteza, por hacer ésta reynar, la qual tyene propiedad que quando los súbditos duermen, ella vela, e ansy vuestra alteza lo deve hacer, pues en verdad nuestro mercenario es, e por esta causa asaz sus súbditos le dan parte de sus frutos e ganancias suias e le syruen éstas a las personas todas las veces que son llamados; pues mire vuestra alteza sy es obligado por contrato callado a los tener e guardar justicia". Jerez Calderón, Pensamiento político y reforma institucional durante la guerra de las Comunidades de Castilla (1520-1521), p. 220. Citado por Pérez, La revolución de las Comunidades de Castilla (1520-1521), p. 120. También se puede ver: Ana I. Carrasco Manchado, "Entre el rey y el reino calladamente está fecho un contrato Fundamentos contractuales de la monarquía Trastámara en Castilla en el siglo XV", en François Foronda (dir.), Avant le contrat social. Le contrat politique dans l'Occident médiéval, XIIIe-XVe siècle, Éditions de la Sorbonne, Paris, 2011, pp. 613-652.

38 En virtud del dicho latino, "pacta sunt servanda”. El Digesto de Justiniano, tomo II, Aranzadi, Pamplona, 1968, edición de Álvaro D’Ors et al., 23, $4,5,1$. 
quebrado el pacto. Este planteamiento es válido en el supuesto de que las dos partes admitan que son iguales y libres para pactar y que ninguna es superior a otra. En el caso histórico que estamos estudiando la realidad fue muy diferente. El protocolo en las sesiones de Cortes mostraba la existencia efectiva de jerarquías que se tenían que respetar. Al mismo tiempo, se escenificaba una separación casi total entre el rey y el pueblo. Por lo tanto, las partes que concurrían a las Cortes no eran iguales ni tampoco libres para pactar. Esta desigualdad social, que se consideraba natural, no se podía ignorar y suprimir. Lo que se pretendió en las Cortes de Santiago y La Coruña fue una ficción que como tal no era posible llevarla a la práctica. La división estamental y jerárquica de la sociedad de la primera Edad Moderna no admitía esta igualdad, ni un trato entre los estamentos sociales igualitario. La ficción fue mantenida por los comuneros que defendieron la idea de que todos los miembros del cuerpo político eran iguales y libres, por tanto, la representación en Cortes constituía el reino que podía imponerse o tratar de igual a igual al monarca. No obstante, esta rebelión iniciada en las Cortes generó un cambio muy importante en el concepto de monarquía y en la consideración del rey como figura política, que va dejando "de ser un principio constitutivo del universo político para transformarse en principio de organización de los Estados" 39 .

Hemos llamado ficción a esta creencia porque no respondían a la realidad política ni social de la época. Las negociaciones de los comuneros con el Almirante de Castilla, Fadrique Enríquez de Velasco (14601538) fueron un fiel reflejo de cuán alejadas estaban las posiciones y, también, cómo los comuneros tenían una visión de su posición muy diferente a la que planteaba el monarca y su entorno ${ }^{40}$. Lo más grave era que cada parte implicada en la negociación hablaba un lenguaje que el otro no comprendía o, dicho de otra forma, los referentes y los contenidos de las palabras eran diferentes para uno y para otro. El entendimiento no fue posible.

Las negociaciones se desarrollaron en dos entrevistas, quizás en dos días distintos sobre el 20 de noviembre de 1520. En ellas intervinieron de un lado el Almirante y de otro una delegación de la Junta compuesta por Antonio de Quiñones (circa s. XV-XVI), Diego de Esquivel (circa s. XV-XVI) y fray Pablo de León (Pablo de Villegas circa s. XV-XVI) que era el jefe ${ }^{41}$. Entre las dos partes existió un acuerdo de inicio, reconocían la necesidad ineludible de realizar reformas inmediatas en Castilla. Tanto el grupo realista como los representados por la Junta tenían propuestas de interés general. Coincidían en el diagnóstico ${ }^{42}$, pero divergían en qué medios y cómo y cuándo aplicarlos para superar la crisis social, política, económica y jurídica en la que vivía Castilla. Las soluciones que cada parte propuso están fundamentadas en unas ideas políticas sobre la monarquía y la forma de gobernar ${ }^{43}$.

La primera cuestión que se planteó fue que el rey no podía hacer nombramientos tan importantes como el de gobernador y de virreyes sin contar con el reino, es decir, con las Comunidades que ellos representan ${ }^{44}$. Por tanto, cualquier nombramiento que no se ajustara a estas exigencias sería ilegítimo por dos razones. Primero, Carlos I es rey de Castilla junto con su madre, en consecuencia, la necesitaba para hacer los nombramientos. Además, antes de abandonar Castilla para viajar a Alemania, prometió que el gobernador del reino sería alguien natural de Castilla. No cumplió su palabra porque nombró a su preceptor el cardenal Adriano de Utrecht (14591523). Segundo, se rechazaron los nombramientos de estos cargos y de los altos funcionarios, porque el reino era superior al rey. Las Comunidades representan al reino en tu totalidad y el rey tiene la obligación de atender sus exigencias, no al revés.

En esta forma de actuar se ponen en juego ideas políticas fundamentales. Desde el punto de vista antropológico, se proclama la libertad y la igualdad de los súbditos del rey frente al poder regio. Si se admite esto, los súbditos pasan a ser miembros del cuerpo político con capacidad para participar activamente en el gobierno del reino y controlar el desempeño de los cargos públicos. Desde el punto de vista político y jurídico la autoridad de la Comunidad como reino es superior al rey.

El Almirante reaccionó ante esta idea y proclamó la tríada que, para el mismo rey y sus partidarios era la legítima y que siempre se había tomado como tal: "Verdad es que sin apartarme del reyno ni deshazer esta

\footnotetext{
José A. Maravall, Carlos Vy el pensamiento político del Renacimiento, Centro de Estudios Políticos y Constitucionales, Madrid, 1999 , p. 177.

40 Pérez, La revolución de las Comunidades de Castilla (1520-1521), pp. 244-251; Jerez Calderón, Pensamiento político y reforma institucional durante la guerra de las Comunidades de Castilla (1520-1521), pp. 218-221.

41 Pérez, La revolución de las Comunidades de Castilla (1520-1521), pp. 225-248.

42 "Todo lo que señores dezis que conuiene que su magestad haga para remedio del reyno me paresce justo que es confirmar las leyes que tenemos: y alargarlas: y acordarlas según la calidad de cada cosa: porque la mudança de los tiempos esto requiere mas esto que queremos conformémonos á pedirlo no seamos tan diferentes en la forma de pedir, pues en el demandar nos conformamos". Manuel Danvila y Collado, "Contestación que el Almirante de Castilla dio a la carta que la Junta de Tordesillas le escribió en 22 de noviembre de 1520", en Historia crítica y documentada de las Comunidades de Castilla, volumen II, p. 538.

43 "E que aunque nos juntamos en los fines (como he dicho) en los principios y abundancia de los males torna do salió vuestro proposito (metidos en tan hondo mar de yerros). E pues conosceys naturalmente crecen y dellos nasce desconfianza y della perdereys esperança seria bien que antes de llegar á tan baxo punto suba el contrapunto quanto abaxa". Ibid., p. 536.

44 “...en que consiste el verdadero servicio de sus altezas e estén en su firme e santo proposito de no obedecer governador que no fuese puesto á contento del Reyno e conforme a las leyes Reales ni consentir que ningún grande so esta color se apodere del Reyno por los grandes males e daños que de aqui resultarían". Manuel Danvila y Collado, Manifiesto original de la Junta de Tordesillas á las Merindades de Castilla la Vieja, fecha en Tordesillas á 14 de Noviembre de 1520", en Historia crítica y documentada de las Comunidades de Castilla, volumen II, p. 591.
} 
trinidad de dios rey y reyno que tan concebida en mi tengo ..." ${ }^{45}$. Ese era el orden objetivo y fijo al que había que someterse y no se podía alterar, cualquier otro orden político significaba romper con una tradición y traicionar al rey y, por ende, transgredir los mandatos divinos. Nunca el reino puede situarse después de Dios, siempre estará en tercer lugar, porque el rey recibe el poder de lo alto, de Dios, con la obligación (oficio) de reinar y procurar el bienestar del reino.

También negó y se opuso a aceptar que la Junta representara a todo el reino. Primero, por una cuestión cuantitativa, de las dieciocho ciudades con voto en Cortes, sólo catorce se habían unido al movimiento. Segunda, desde el punto de vista territorial ni Andalucía, ni las Vascongadas, ni Asturias y ni Galicia tenían representantes en la Junta. Por tanto, pretender que la Junta y el movimiento de las Comunidades fuera la totalidad del reino y en él estuvieran representados todos los súbditos del monarca era una ficción y, además, una falsedad ${ }^{46}$.

A pesar de las discrepancias manifestadas durante las intervenciones, las partes se esforzaron por llegar a un punto de convergencia entre ambas posturas: "Pues si en todo estamos conforme con vosotros, ¿por qué no nos concertamos en la forma del pedirlo para que tenga fuerça lo que se otorgare?" ${ }^{47}$ El acuerdo se mostró imposible e inalcanzable porque la posición de la Junta era inflexible. El Almirante no dudó en criticar y censurar a los comuneros sus pretensiones: “... que es presuponer quel reyno manda al rey: y no el rey al reyno. Cosa es que jamas fue vista, no se porque vosotros con novedades tan nuevas buscays: y queréis fallar el bien en medio de nuestros males" $"$.

Los representantes de la Junta de Tordesillas estaban planteando un cambio político de gran calado basado en el principio de representación del procurador de las ciudades en las Cortes, la cuestión de la soberanía y la posición del rey en el orden jurídico y político-constitucional. Este proyecto reformista abarcaba tanto el ámbito de la política como a la misma estructura institucional del reino y a la sociedad. Los comuneros pretendían poner por encima del rey la autoridad de las Cortes y sus representantes y suprimir en la monarquía castellana las clases privilegiadas por naturaleza o por pertenecer a un determinado estamento social ${ }^{49}$. La cuestión fundamental que se planteó fue: ¿por qué y cómo se justifican estos cambios? ¿Por qué se expusieron en este momento? Porque las esperanzas depositadas en la llegada de un nuevo rey se vieron defraudadas. Él no se rodeó de colaboradores pertenecientes a la burguesía asentada en las ciudades. Volvió a contar con la nobleza que se puso del lado del rey porque quería preservar sus status y sus privilegios y, sobre todo, con el grupo de extranjeros que le acompañó en su llegada a Castilla. En definitiva, gobernó con una oligarquía de nobles y altos eclesiásticos. Frente a esta forma de actuar, las Comunidades trataron de fortalecer la participación política del estamento popular.

Las discrepancias sobre las ideas y la función política de cada grupo social hay que buscarla en la primera controversia entre los castellanos y el propio rey Carlos I. Esta tuvo lugar cuando llegaron noticias a Castilla de que el príncipe Carlos se había proclamado rey de Castilla en la iglesia de Santa Gúdula después del funeral celebrado en memoria de su abuelo Fernando el Católico (1452-1516). Este hecho ha sido calificado por algunos historiadores como un auténtico golpe de Estado ${ }^{50}$.

La posición de los súbditos del rey de Castilla era la siguiente. La reina Juana I (1479-1555) estaba viva, recluida o encarcelada, según se mire, en Tordesillas e incapacitada para ejercer responsabilidad alguna de gobierno. Se decía que no quería y no podía gobernar. En su lugar habían desempeñado la regencia primero su padre, el rey Fernando el Católico y, después, el Cardenal Cisneros (Gonzalo Jiménez de Cisneros, 14361517). El pueblo sabía que Castilla tenía una reina viva, pero también que su enajenación le impedía asumir las responsabilidades inherentes a tan alto cargo.

La proclamación de Carlos provocó indignación, rechazo y conmoción en Castilla. Pedro Mártir de Anglería informó por extenso a su pariente, obispo de Tuy y hombre de confianza del príncipe Carlos, Luis Marliani (circa s.XV-1521), sobre las altas expectativas que estaba generando la llegada del príncipe a España. Le aconseja que no se proclamara "Rey de las Españas" porque su madre aún vivía. No era necesario, en estas circunstancias, ser rey para gobernar, podría hacer como príncipe. Castilla estaba deseosa de conseguir la estabilidad política y social después de muchos años de cambios y regencias. Por eso los castellanos estaban dispuestos a aceptar a un rey que respetara sus leyes y sus costumbres. Este monarca no se debían traspasar algunos límites porque "la perversión de las leyes suele convertir el amor en odio" ${ }^{51}$. La advertencia se puede

\footnotetext{
Danvila y Collado, "Contestación que el Almirante de Castilla dio a la carta que la Junta de Tordesillas le escribió en 22 de noviembre de 1520 ”, p. 537.

46 “...porque devrian vuestras cosas señores limitarse en esta parte diziendo fulano y fulano procuradores de tales cibdades que aqui nos juntamos e no firmemente llamaros procuradores de todo el reyno". Ibid., p. 539.

Ibid., p. 541.

Ibid., p. 536.

49 Jerez Calderón, Pensamiento político y reforma institucional durante la guerra de las Comunidades de Castilla (1520-1521), p. 199. Es muy acertada la tesis del libro de Gutiérrez Nieto, Las comunidades como movimiento antiseñorial, pp. 232-322.

50 Manuel Giménez Fernández, Bartolomé de Las Casas, vol. I, CSIC-Escuela de Estudios Hispanoamericanos, Sevilla, 1953, pp. 72-74; Ramón Menéndez Pidal, "Un imperio de paz cristiana”, en Historia de España. Vol. XVIII, Espasa Calpe, Madrid, 1966, p. XIV; Pérez, La revolución de las Comunidades de Castilla (1520-1521), pp. 78, 79, 82, 115 y 535.

51 Pedro Mártir de Anglería, “Carta 568”, en Epistolario, vol. III, , ed. por J. López de Toro, Imprenta de Góngora, Madrid, 1956 , pp. $221-222$.
} 
resumir en que, si no gobernaba buscando el bien de los súbditos, éstos se rebelarían contra el monarca deslegitimando su reinado y a su persona para gobernar.

Nadie dudaba sobre los derechos del príncipe Carlos para ser en el futuro rey. Lo que se criticó por parte de los castellanos fue la urgencia en querer ser reconocido como Rey de las Españas en vida de su madre, cuando ni era necesario, ni era oportuno. Lo único que podía causar este paso era división y animadversión hacia su persona ${ }^{52}$. Muestra de la delicadeza con que se toma el asunto es la carta que escribió el Consejo Real al príncipe que recoge Prudencio Sandoval ${ }^{53}$. En la carta se relatan los problemas, las divisiones y los abusos que se están produciendo en el Reino y se le suplica que venga cuanto antes para que estos desórdenes no se generalicen y se castigue a los culpables con severidad, porque sus acciones constituyen un "menosprecio a vuestra Real justicia"54.

Al reglón seguido se le aconseja que no se titule rey:

...nos pareció que no devia V. A. hazer ni conuenia que se hiziesse para lo de Dios: y para lo del mundo: porque teniendo como V. A. tiene tan pacíficamente sin contradicción de estos Reynos, que en efecto desde luego libremente son vuestros ..., no ay necessidad en vida de la Reyna nuestra señora vuestra madre intitular Rey, pues lo es. Porque aquello seria disminuyr el honor y la reuerencia que se deue por ley divina, y humana, a la Reyna nuestra Señora y vuestra madre, y venir sin fruto ni efeto ninguno contra el mandamiento de Dios, que os ha de prosperar y guardar para reynar por muchos y largos años ${ }^{55}$.

Estas líneas contienen una idea muy importante. Si Carlos se proclamaba rey, estaba imponiéndose a los demás, es decir, usaba su poder para convertirse en monarca. En cambio, si esperaba a que la proclamación se realizara en Castilla, entonces estaba recibiendo el reconocimiento por parte de la sociedad castellana y se investiría no sólo de poder como rey, sino que se le reconocía autoridad para gobernar. La diferencia es imponerse o bien obtener el reconocimiento necesario para ser rey. Una vez más aflora la distinción entre auctoritas y potestas. La autoridad (auctoritas) es, pues, un saber socialmente reconocido. Esto implica libertad, porque el reconocimiento es una aceptación libre por parte de otro. La cantidad de libertad en juego está en función de la auctoritas en el ámbito público dentro del marco de la libertad reconocida. La potestad (potestas), en cambio, es el poder socialmente reconocido.

¿Qué sentido tenía esta distinción? Convertirse en garante de la libertad de los súbditos gobernados por un rey. Por cuanto que éstos, ante abusos de poder, podían reclamar y apelar a la autoridad del monarca o de las Cortes, quien mediante sus consejos y declaraciones podía influir y controlar el poder, y encauzar los abusos que se habían cometido.

¿Por qué criticó una parte de los castellanos la proclamación de Carlos como rey? Porque era jurídicamente incompleto e insuficiente para ejercer las funciones como monarca. Los súbditos de Castilla — también los de Aragón - tenían que jurar fidelidad al nuevo monarca y él jurar respetar los fueros y leyes del reino. Para completar su proclamación, Carlos tenía comparecer y ser jurado en cada una de las Cortes. Cada reino tenía sus Cortes y el juramento se hacía en ellas. Las Cortes eran para reino, no un instrumento del rey.

Este hecho moverá a los comuneros a plantear la legalidad y la legitimidad dinástica en la persona de la reina propietaria de Castilla, Juana I a la que consideran capaz de gobernar si se le permite salir de su prisión de Tordesillas y se la trata con los remedios médicos adecuados. Antes de que los comuneros se encuentren con la reina de Castilla en Tordesillas, acaecieron otros hechos que fueron, junto con el que hemos expuesto, los detonantes de la rebelión.

Se ha hecho referencia a la elección como emperador de Carlos. No podemos decir que fue una sorpresa para la Casa de Habsburgo. Su nominación se venía trabajando desde hacía tiempo. La proclamación como rey de Castilla y de Aragón, sin duda, ayudó a conseguirla, porque sus otros dos oponentes, Francisco I (14941547) y Enrique VIII (1491-1549), se presentaban como reyes de Francia y de Inglaterra, respectivamente. La consecuencia inmediata de la elección fue la necesidad de disponer de dinero para pagar a los electores, viajar a Alemania con un nutrido séquito y financiar los fastos propios de la elección. ¿De dónde podía conseguir ese dinero el joven Emperador? Pues de sus reinos patrimoniales, básica y exclusivamente de Castilla. La convocatoria de las Cortes de Santiago de Compostela, continuada en La Coruña, obedeció solo a la necesidad de conseguir un servicio extraordinario para sufragar los costes de la elección. Estos nuevos tributos tenían una relación directa con el reconocimiento de la autoridad real y con un cambio en la condición del procurador, que, como hemos visto, se consideraba el representante de una ciudad con un mandato imperativo.

22 Prudencio de Sandoval, en Historia de la vida y hechos del Emperador Carlos V, máximo, fortísimo, rey católico de España y de las Indias, Islas y Tierra firma del mar Océano, ed. de Carlos Seco Serrano, Ediciones Atlas, Madrid, 1955, Primera parte, 2. 4, p. 59, relata la proclamación como Rey de España en Bruselas; Alonso de Santa Cruz, en Crónica del Emperador Carlos V, de Ricardo Beltrán y Rózpide y Antonio Blázquez y Delgado-Aguiler, prólogo de Francisco de Laiglesia y Auser, Imprenta del Patronato de Huérfanos de Intendencia e Intervención Militares, Madrid, 1920-1925, pp. 108-113, añade que el hecho causó conmoción, indignación e ira contra el príncipe Carlos en Castilla.

3 Sandoval, Historia de la vida y hechos del Emperador Carlos V, Primera parte, 2. 4, pp. 62-64.

54 Ibid., Primera parte, 2. 4, p. 63.

55 Ibidem. 
Terminaremos este epígrafe señalando la oposición de los castellanos a la elección imperial y a que el Reino de Castilla formara parte de una entidad supranacional. Durante el reinado de los Reyes Católicos se fueron incorporando a la Corona diversos territorios que fueron conquistando y descubriendo. Al final del reinado del Fernando el Católico se puede afirmar que se había constituido una monarquía universal que tenía posesiones en Europa, África y América ${ }^{56}$. La elección de Carlos I como emperador, incorporó a su cuantiosa herencia el título que le convertía en un monarca superior a todos los demás. Dentro de este proyecto Castilla constituía un reino en el que podía conseguir los recursos necesarios para realizar su política imperial. Para los castellanos las pretensiones de su rey y emperador las consideraban de otra manera. Castilla en el conjunto de los reinos de Carlos I sería un apéndice o una prótesis extraña que no se identificaría totalmente con el proyecto político que el monarca planeaba.

En este caso se produjo no sólo un choque de mentalidades, sino también una diferente apreciación de lo que es el imperio. Para Carlos V es la culminación de un ambición familiar y personal. Para los castellanos una amenaza a la independencia del reino y a la libertad de los súbditos del rey. Sin duda, se reconocía que el rey de Castilla ganaba en dignidad, pero los castellanos perdían a la persona que tenía que gobernarles y regir toda la extensión territorial que correspondía al heredero de los Reyes Católicos.

La colisión se produjo entre una idea de imperio europeo-cristiano en el que su centro de gravedad estaba en Alemania, que convertiría a Castilla en una pieza más de todo el puzle; y otra idea de monarquía universal que tuviera su centro en Castilla en la que el monarca gobernaba el reino y desde él todos los territorios que lo componen. Esta última idea se basaba en una concepción de la monarquía en la que el rey es rey de Castilla y desde su propiedad gobernaba su territorio y a sus súbditos. Ser emperador de Alemania, como se conocía en esa época, no era más que un título honorífico ${ }^{57}$, que no aportaba nada a Castilla. En cambio, sí le iba a suponer aportar grandes cantidades de dinero y disponer de personas para nutrir las filas de los ejércitos para mantener, defender el y repeler los ataques de los enemigos del imperio. Los castellanos no se equivocaron y el tiempo les dio la razón.

\section{3. ¿Revuelta, movimiento social o revolución?}

En el recorrido que se ha realizado en el epígrafe primero, se ha visto que unos autores se inclinan por calificar el movimiento comunero como una revolución. Otros lo consideraron un movimiento social que pretendía realizar reformas de profundo calado en la institución monárquica.

Autores modernos como José A. Maravall, Joseph Pérez, Juan Ignacio Gutiérrez Nieto, son partidarios de ver en el movimiento comunero una revolución y la califican como la primera revolución moderna. Esta revolución pretendió evitar una concentración excesiva de poder en manos del monarca y de sus colaboradores, que cercenara las libertades que se habían ganado las ciudades con su desarrollo industrial y su actividad mercantil. En otras palabras, los comuneros trataron de evitar que la monarquía de Carlos I se convirtiera en una monarquía absoluta que provocara la decadencia de las ciudades y de las instituciones políticas que le servían de representación ${ }^{58}$. Los comuneros tomaron conciencia de la importancia que tiene la Comunidad como cuerpo político por encima de la noción tradicional de reino. El carácter representativo de la Comunidad es superior al del monarca. Este sentido de pertenencia a una estructura social y política que le representa y le ampara, exige que las instituciones no estuvieran controladas por extranjeros y que los cargos de gobierno de la Comunidad los desempeñen los naturales del reino ${ }^{59}$. En tercer lugar, como señaló con acierto Gutiérrez Nieto, es una revolución antiseñorial, contra los privilegios y la actitud de la nobleza. Unida a una rebelión contra los impuestos y los tributos abusivos, como el servicio para realizar el viaje a Alemania para ser proclamado Emperador, y contra una forma de gobierno que impida y excluya la participación del pueblo en los asuntos de Estado ${ }^{60}$.

Un grupo de autores más actuales han revisado estas tesis y han propuesto que los comuneros no llevaron a cabo una revolución en el sentido moderno del término, sino que plantearon reformas profundas y de gran calado en la constitución política de una monarquía. Julio Valdeón (1936-2009) insistió en la idea de las Comunidades como la última revuelta medieval ${ }^{61}$, tradicional, pero no retrógrada. En la revisión sobre el carácter y el sentido del movimiento comunero, sobre si se puede o no calificarlo de revolución, han participado varios historiadores, entre ellos Pablo Sánchez León, que afirma que es una revuelta urbana y no una revolución, porque unos nobles o caballeros de las ciudades de Castilla no podían tener la idea de llevar a cabo unas reformas que cambiaran

\footnotetext{
Salvador Rus Rufino, Una biografia política de Fernando el Católico. La constitución de una monarquía universal, Tecnos, Madrid, 2016.

Henry Kamen, Imperio. La forja de España como potencia mundial, Aguilar, Madrid, 2006, p. 26; Calderón, Pensamiento político y reforma institucional durante la guerra de las Comunidades de Castilla (1520-1521), pp. 133-135.

Maravall, Las comunidades de Castilla, pp. 33, 34, 116, 117, 153, 154 y 212.

Ibid., pp. 55-62.

Ibid., pp. 191-195; Gutiérrez Nieto, Las comunidades como movimiento antiseñorial; Tierno Galván, "De las comunidades o la historia como proceso", en Escritos (1950-1960), pp. 312-314.

61 Julio Valdeón Baruque, “¿La última revuelta medieval?”: Cuadernos Historia 16, n. ${ }^{\circ} 24$ (1985), pp. 4-12.
} 
tanto la sociedad como en una revolución ${ }^{62}$. En el mismo sentido se pronunció el historiador Máximo Diago Hernando ${ }^{63}$. Más desarrollada está la tesis de Pablo Fernández Albadalejo, al matizar el mismo objeto de debate sobre el carácter feudal o revolucionario de las Comunidades, subrayando más la restauración del orden jurídico que la nota revolucionaria ${ }^{64}$.

José J. Jerez en un libro publicado en el año 2007 analizó con exhaustividad los antecedentes y la evolución de las ideas políticas y jurídicas en los años previos y posteriores a la revuelta de las Comunidades. La tesis del trabajo es demostrar que la obra jurídica comunera no llegó a ser una constitución en el sentido moderno del término, sino que los comuneros reivindicaron la vigencia de las leyes del reino castellano, que eran una especie de leyes fundamentales que ordenaban la vida política y jurídica en el Reino de Castilla, que nadie podía cambiar unilateralmente. La revuelta se justificó porque se acusó al rey Carlos I y a sus colaboradores, sobre todo los flamencos, de no someterse a estas leyes ${ }^{65}$. Parecida orientación subyace en la interpretación de José L. Bermejo Cabrero, con mayor atención a la intención legitimadora de los comuneros sobre la base de la tradición jurídica castellana ${ }^{66}$.

Desde este punto de vista fue una rebelión que buscaba introducir profundos cambios políticos, institucionales y sociales que no afectaban a la forma de Estado, pero sí al desempeño del gobierno y al ejercicio del poder por parte del rey. Las Comunidades no constituyeron una revolución porque no luchó por cambiar la forma de Estado, como sucedió en otras revoluciones de la Edad Moderna posteriores. Aceptaron la monarquía y al monarca que lucía la corona. Ésta siguió siendo una monarquía, pero se quiso avanzar en un proceso de participación democrática (la palabra es anacrónica, pero expresa bien el sentido de las pretensiones comuneras) del pueblo, el común, y de todos los estamentos sociales en el gobierno del reino. Así se volvía al planteamiento de que el poder está en el pueblo y éste lo cede al rey.

\section{Conclusiones}

Podríamos preguntarnos si los comuneros estaban proponiendo una constitución nueva o una reforma profunda de las leyes y las normas que ordenaban el gobierno de la monarquía. Si se acepta que las Comunidades en sus sucesivas instrucciones pretendieron imponer una nueva constitución política, entonces, los comuneros realizaron una revolución que deseaba cambiar el régimen político. Si no admitimos el cambio constitucional, habrá que aceptar que las Comunidades fueron una rebelión que pretendió realizar reformas políticas y, también, sociales profundas y necesarias.

Se ha puesto el acento en que los comuneros propusieron importantes cambios constituciones, "sin duda, bajo la superficie de la rebelión comunera ... hervía el propósito, no de conservar libertades amenazadas, como se dice, sino de innovar fundamentalmente la constitución de España"67. Las propuestas, las normas, las declaraciones, los capítulos, los textos y las intervenciones de los comuneros apuntaron directamente a realizar una reforma de la monarquía, pero no sustituir a la monarquía como forma de Estado.

El establecimiento de la Santa Junta como órgano ejecutivo, en principio, y, posteriormente, en legislativo al cambiar su denominación por Cortes y Junta General del Reino, vino provocado por dos hechos. El primero, por el viaje de Carlos I a Alemania que se interpretó como una falta de atención a las reiteradas peticiones que los procuradores realizaron en las Cortes. El segundo, por la forma de gobernar de su regente, el cardenal Adriano, y de los virreyes, el condestable de Castilla y el almirante de Castilla. Esta situación que rechazaron los comuneros, les llevó a buscar una alternativa política para gobernar.

Una prueba evidente de lo que hemos afirmado hasta ahora es la siguiente. Los comuneros criticaron la autoproclamación de Carlos I como rey de Castilla y, también, su posterior viaje a Alemania para ser proclamado rey de los Romanos ${ }^{68}$, abandonando sus obligaciones en manos de un gobernador extranjero. Ante estas dos irregularidades los comuneros buscaron una nueva legitimidad y legalidad para justificar su rechazo a la política de Carlos I. Ésta la encontraron en la figura de la reina Juana I. No trataron de constituir

62 Pablo Sánchez León, Absolutismo y Comunidad. Los orígenes sociales de la guerra de los comuneros de Castilla, Siglo XXI Editores, Madrid, 1998; Pablo Sánchez León, "La Constitución histórica del sujeto comunero: orden absolutista y lucha por la incorporación estamental en las ciudades de Castilla, 1350-1520", en Fernando Martínez Gil (ed.), Poder, conflicto y revuelta en la España de Carlos I, Ediciones Universidad de Castilla-La Mancha, Cuenca, 2002, pp. 159-208.

63 Máximo Diago Hernando, Le Comunidades di Castiglia (1520-1521). Una rivolta urbana contro la monarchia degli Asburgo, Edizioni Unicopli, Milano, 2001.

64 Pablo Fernández Albadalejo, Fragmentos de Monarquía, Alianza Editorial, Madrid, 1992, p. 54.

65 Jerez Calderón, Pensamiento politico y reforma institucional durante la guerra de las Comunidades de Castilla.

${ }^{66}$ José L. Bermejo Cabrero, "La gobernación del reino en las Comunidades de Castilla": Hispania, n. ${ }^{\circ} 124$ (1973), pp. 249-264.

67 Ramón Menéndez Pidal, "Carlos V y las comunidades vistas a nueva luz documental", en El Padre Las Casas y Vitoria con otros temas de los siglos XVI y XVII, Espasa Calpe, Madrid, 1958, p. 82. La misma idea la defendió Luis Bonilla, Las revoluciones españolas en el siglo XVI, Editorial Guadarrama, Madrid, 1972, pp. 117-120 y 223-225.

68 El rey de los Romanos era el rey elegido emperador del Sacro Imperio Romano Germánico, pero que todavía no había sido coronado y ungido por el papa. 
una república como las italianas, ni instaurar otra forma de Estado, optaron por la monarquía siguiendo la línea dinástica de la Casa Trastámara que había gobernado Castilla desde los tiempos de Enrique II (1334-1379).

En el verano de 1520 se reunieron en Ávila y establecieron un órgano que se llamó Santa Junta, que se atribuyó la representación de todo el cuerpo político ${ }^{69}$. Desde el principio trató de cubrir una necesidad asumiendo el gobierno de Castilla en nombre de la reina Juana I, porque su hijo había abandonado su reino y ella se mostró durante un tiempo ilusionada y capaz de asumir sus responsabilidades como reina. En esta situación su poder y la legitimidad de sus decisiones contaron con el respaldo verbal de la reina, hasta que se negó a firmar cualquier documento, de los municipios y ciudades representadas en ella ${ }^{70}$.

Los comuneros lucharon por alcanzar la libertad política y social de los súbditos del rey, que no querían dejar de ser súbditos, sino que deseaban ser gobernados por un monarca que asumiera las responsabilidades y los deberes inherentes a su condición de rey y no estuviera ausente de su reino. Al mismo lucharon para consolidar e incrementar la participación de los súbditos en la gestión de gobierno a través de las instituciones políticas existentes. La propuesta se fundamentó en dos principios básicos. De un lado, la libertad del individuo para decidir si quería o no asumir la responsabilidad y el compromiso de participar en la vida política; de otro, la igualdad porque todos los súbditos del rey y miembros del cuerpo político se consideraban iguales sin distinción de rango, posición social y nivel de riquezas ${ }^{71}$. Libertad e igualdad formaban un binomio que permitía construir una sociedad más democrática, más participativa y sobre todo más unida y comprometida con el proyecto político. Unión porque los ciudadanos libres e iguales pueden comunicarse sus propuestas, discutirlas, discrepar y llegar a un acuerdo. Compromiso que se manifestaba en la capacidad para galvanizar todas las fuerzas y todas las actuaciones hacia un mismo objetivo compartido, asumido y consensuado por todos. De esta forma, el común, la Comunidad podía considerarse como el auténtico reino que abarcaba a todos los que vivían en ese territorio y estaban regidos por las mismas leyes. El cuerpo político de la Comunidad era superior al poder representado por una sola persona y sus colaboradores. Es decir, el reino mandaba al rey y no el rey al reino. Eso era, como hemos visto al principio, una especie de herejía política.

Los comuneros querían una monarquía democrática con un poder desconcentrado y compartido. De esta forma pretendieron acabar con la oligarquía de nobles y altos eclesiásticos — que habían traicionado al movimiento de las Comunidades para preservar sus privilegiosun movimiento antiseñorial. Instaurar esta comunidad no implicaba realizar una revolución. Esta concepción de la política y de la monarquía se fundamentó en una tríada unida y muy fuerte compuesta por el territorio (reino o Comunidad), súbditos que participan en el gobierno porque son libres e iguales y realizan proyectos comunes, dentro de un orden jurídico y unas leyes iguales para todos, que regulan la participación y la vida política. Una estructura parecida a la de pólis griega que estaba compuesta por la misma pólis (ciudad-estado), el polités (ciudadano) y por la politeía (la constitución política y cuerpo legislativo).

Las Comunidades no constituyeron sólo una revolución, porque no se luchó por cambiar la forma de Estado, como sucedió en otras revoluciones posteriores. La sensación de transformación sistémica de las aspiraciones políticas se consiguió más por la vía de cambios acumulativos que permitieran la perduración parcial de algunas expectativas, que por la vía revolucionaria. El proceso temporal seguido se puede resumir de la siguiente manera. Oposición un servicio - impuestos extraordinarios-que nada tenían que ver con los asuntos del reino de Castilla. Rebelión contra una forma de gobierno que estaba en manos de extranjeros y de personas e instituciones que los comuneros no reconocían. Una lucha armada para conseguir los objetivos y el proyecto político propuesto. Sólo al final del proceso podemos ver reacciones y propuestas revolucionarias porque las posiciones se habían radicalizado.

Los comuneros aceptaron la monarquía y al monarca que lucía la corona. Lo que se criticó y trató de sustituir fue la forma de gobierno que Carlos I había instaurado. La forma del Estado siguió siendo una monarquía, pero se quiso avanzar en un proceso de participación democrática del pueblo, de todo el cuerpo político. Así se volvía al planteamiento paccional propio de una aspiración contractualista de que el poder lo tenía el pueblo que lo entregaba al rey mediante un pactum subiectionis, muy matizado por la reserva de participación política a favor del estamento ciudadano. Un acuerdo entre el rey y los súbditos que imponía límites al ejercicio del poder político con el fin de realizar el ideal de buen gobierno, en el que estaba implicada todo el reino, toda la Comunidad: reyes, nobles, clero y pueblo. El pacto se basó en cinco principios: la concordia, el respeto a la

69 Máximo Diago Hernando, "La representación ciudadana en las asambleas estamentales castellanas: Cortes y Santa Junta Comunera. Análisis comparativo del perfil sociopolítico de los procuradores”: Anuario de Estudios Medievales, vol. 34, n. ${ }^{\circ} 2$ (2004), pp. 599-665, es quizás el estudio más completo y documentado sobre esta institución política.

70 Danvila y Collado, Historia crítica y documentada de las Comunidades de Castilla, volumen II, pp. 76-81, donde se recoge el texto que la Alianza y hermandad jurada que las ciudades y villas del Reino realizaron en Tordesillas el 25 de septiembre de 1520; Pedro Mexía, Historia del Emperador Carlos V, ed. de J. M. Carriazo y Arroquia, Espasa Calpe, Madrid, 1945, p. 170.

71 El movimiento de las Comunidades fue referenciado por Karl Marx (1818-1883): “....el pretexto inmediato [de la guerra], como a menudo ocurre, fue facilitado por la clique que bajo los auspicios del cardenal Adriano exasperó a los castellanos por su insolente rapacidad, vendiendo cargos públicos al mejor postor y haciéndose culpable de manifiestos y cohechos de la justicia. Pero la oposición contra la camarilla flamenca no pasó de la superficie del movimiento. En el fondo se trataba de la defensa de las libertades de la España medieval contra los abusos del absolutismo moderno". Karl Marx, Revolución en España, ed. de Manuel Sacristán, Ediciones Ariel, Barcelona, 1970, pp. 70-71. 
ley, la justicia, la lealtad y la sabiduría y la capacidad de las partes para llegar a entenderse y gobernar el reino de manera adecuada y justa ${ }^{72}$.

La consideración del proceso de las Comunidades en su totalidad nos muestra diversas fases y diferentes reformas que, en el último fotograma por vía de transformaciones acumulativas, exhiben una imagen de revolución que no tuvo prima facie y tampoco se le puede atribuir en el proceso.

\section{Referencias bibliográficas}

Altamira, Rafael, Historia de la civilización española, Manuel Soler, Barcelona, 1901.

Argüelles, Agustín de, Discurso preliminar a la Constitución de 1812, introducción de Luis Sánchez Agesta, Centro de Estudios Constitucionales, Madrid, 1981.

Azaña, Manuel, Plumas y palabras, Crítica, Barcelona, 1990.

Azcárate, Gumersindo de, Minuta de un testamento (Ideario del krausismo liberal), ed. de José Luis Monereo, Editorial Comares, Granada, 2004.

Ballester Rodríguez, Mateo, "Comunidad, patria y nación como fuentes de la legitimidad política en las Comunidades de Castilla (1520-1521)": Revista de Estudios Politicos, n. ${ }^{\circ} 153$ (2011), pp. 215-249.

Balmes, Jaime, El protestantismo en comparación con el catolicismo en sus relaciones con la civilización europea, en Obras Completas, vol. VIII, tomo IV, ed. de Ignacio Casanovas, Biblioteca Balmes, Barcelona, 1925.

Bayona Aznar, Bernardo, Pactismo y Teocracia. Las dos caras del pensamiento politico de Francesc Eximenis, Tecnos, Madrid, 2019.

Bermejo Cabrero, José L., "La gobernación del reino en las Comunidades de Castilla": Hispania, n. 124 (1973), pp. 249-264.

Berzal de la Rosa, Enrique, Los comuneros. De la realidad al mito, Silex, Madrid, 2008.

Bofarull y Romañá, Manuel de, Las antiguas Cortes. El moderno Parlamento. El régimen representativo orgánico, s.n., Madrid, 1912.

Bonilla, Luis, Las revoluciones españolas en el siglo XVI, Editorial Guadarrama, Madrid, 1972.

Cánovas del Castillo, Antonio, "De las ideas políticas de los españoles durante la Casa de Austria (Apuntes críticos)": Revista de España, tomo IV, n. ${ }^{\circ} 16$ (1868), pp. 503-576.

Carrasco Manchado, Ana I., "Entre el rey y el reino calladamente está fecho un contrato. Fundamentos contractuales de la monarquía Trastámara en Castilla en el siglo XV", en François Foronda (dir.), Avant le contrat social. Le contrat politique dans l'Occident médiéval, XIIIe-XVe siècle, Éditions de la Sorbonne, Paris, 2011.

Castro, Américo, La Celestina como contienda literaria, Revista de Occidente, Madrid, 1965.

Colmeiro, Manuel, De la Constitución y del Gobierno de los reinos de León y Castilla, Imprenta de J. Martín Alegría, Madrid, 1855

Costa, Joaquín, Historia crítica de la revolución española, ed. de A. Gil Novales, Centro de Estudios Constitucionales, Madrid, 1992.

Danvila y Collado, Manuel, Historia crítica y documentada de las Comunidades de Castilla, volumen II, Establecimiento Tipográfico de la viuda e hijos de M. Tello, Madrid, 1898.

Diago Hernando, Máximo, Le Comunidades di Castiglia (1520-1521). Una rivolta urbana contro la monarchia degli Asburgo, Edizioni Unicopli, Milano, 2001.

—, "La representación ciudadana en las asambleas estamentales castellanas: Cortes y Santa Junta Comunera. Análisis comparativo del perfil sociopolítico de los procuradores": Anuario de Estudios Medievales, vol. 34, n. 2 (2004), pp. 599-665.

D’Ors, Álvaro et al. (eds.), El Digesto de Justiniano, tomo II, Aranzadi, Pamplona, 1968.

Du Hamel, Víctor Auguste, Histoire constitutionnelle de la monarchie espagnole, depuis l'invasion des hommes du Nord jusqu'à la mort de Ferdinand VII, 411-1833, Libraire D'Amyot, Paris, 1845 [ed. esp.: Historia constitucional de la Monarquía española: desde la invasión de los bárbaros hasta la muerte de Fernando VII (411-1833), Mellado Editor, Madrid 1848].

Fernández Albadalejo, Pablo, Fragmentos de Monarquía, Alianza, Madrid, 1992.

Ferrer del Río, Antonio, Decadencia de España. Primera parte. Historia del Levantamiento de las Comunidades de Castilla 1520-1521, Establecimiento Tipográfico de Mellado, Madrid, 1850.

Ganivet, Ángel, Idearium español, Espasa-Calpe, Madrid, 1990.

García Gallo, Alfonso, "El pactismo en el Reino de Castilla y su proyección en América", en El pactismo en la historia de España, Instituto de España, Madrid, 1980.

Giménez Fernández, Manuel, Bartolomé de Las Casas, vol. I, CSIC-Escuela de Estudios Hispanoamericanos, Sevilla, 1953.

72 Bernardo Bayona Aznar, Pactismo y Teocracia. Las dos caras del pensamiento político de Francesc Eximenis, Tecnos, Madrid, 2019, pp. 82-87; Alfonso García Gallo, "El pactismo en el Reino de Castilla y su proyección en América", en El pactismo en la historia de España, Instituto de España, Madrid, 1980, pp. 143-168. 
Godechot, Jacques, Les Révolutions 1770-1799, Presses Universitaires de France, Paris, 1965.

Guevara de, Antonio, Epístolas Familiares, Casa Iacobo Meurcio, Anveres, 1633.

Gutiérrez Nieto, José I., Las comunidades como movimiento antiseñorial, Planeta, Barcelona, 1973.

Häbler, Konrad, “Zur Geschichte der kastilischen Comunidades. 1520-21”: Historische Zeitschrift, 95 (1905), pp. $385-$ 434.

Haliczer, Stephan, Los Comuneros de Castilla: la forja de una revolución (1475-1521), Universidad de Valladolid, Valladolid, 1987.

Jerez Calderón, José J., Pensamiento político y reforma institucional durante la guerra de las Comunidades de Castilla (1520-1521), Marcial Pons, Madrid, 2007.

Kamen, Henry, Imperio. La forja de España como potencia mundial, Aguilar, Madrid, 2003.

Lafuente, Modesto, Historia General de España, tomo XI, Establecimiento Tipográfico de Mellado, Madrid, 1858.

Latimer Seaver, Henry, The Great Revolt in Castile. A Study of the Comunero Movement of 1520-1521, Constable \& Company Limited, London, 1930.

López Vela, Roberto, “Las Comunidades: ¿lucha por la libertad o feudalismo concejil? El debate sobre la revolución’ en la historiografía de la Restauración”: Investigaciones Históricas: época moderna y contemporanea, n. ${ }^{\circ} 24$ (2004), pp. $105-138$.

Macías Picavea, Ricardo, El problema nacional, Librería General de Victoriano Suárez, Madrid, 1899.

Maravall, José A., Las comunidades de Castilla. Una primera revolución moderna, Alianza Editorial, Madrid, 1979.

—, Carlos Vy el pensamiento político del Renacimiento, Centro de Estudios Políticos y Constitucionales, Madrid, 1999.

Martínez de la Rosa, Francisco, Bosquejo histórico de las Comunidades, en Obras Dramáticas, Espasa Calpe, Madrid, 1954.

Martínez Gil, Fernando, "La memoria histórica de las comunidades en los siglos XVI y XVII", en Carlos I y su tiempo: actas del Congreso Beresit III, vol. 3, Archivo Municipal de Toledo, Toledo, 2002.

Martínez Marina, Francisco, Teoría de las Cortes o Grande Juntas nacionales de los reinos de León y Castilla: monumentos de su Constitución política y de la soberanía del pueblo, con algunas observaciones sobre la Ley Fundamental de la monarquía española, sancionada por las Cortes generales y extraordinarias, y promulgada en Cádiz a 19 de marzo de 1812, Imprenta de Fermín Villalpando, Madrid, 1813, tres tomos.

Mártir de Anglería, Pedro, Epistolario, volumen III, ed. de J. López de Toro, Imprenta de Góngora, Madrid, 1956.

Marx, Karl, Revolución en España, ed. de Manuel Sacristán, Ediciones Ariel, Barcelona, 1970.

Menéndez Pelayo, Marcelino, Historia de los heterodoxos españoles, Biblioteca de Autores Cristianos, Madrid, $1965-$ 1967, dos tomos.

Menéndez Pidal, Ramón, “Carlos V y las comunidades vistas a nueva luz documental”, en El Padre Las Casas y Vitoria con otros temas de los siglos XVI y XVII, Espasa Calpe, Madrid, 1958.

—, "Un imperio de paz cristiana", en Historia de España, vol. XVIII, Espasa Calpe, Madrid, 1966.

Mexía, Pedro, Historia del Emperador Carlos V, ed. de J. M. Carriazo y Arroquia, Espasa Calpe, Madrid, 1945.

Pérez, Joseph, "Pour une nouvelle interpretation des 'Comunidades' de Castilla": Bulletin Hispanique, 65, n. 3-4 (1963), pp. 238-283.

—, "Tradición e innovación en las Comunidades de Castilla", en Hommage des hispanistes français à Noël Salomon, Editorial Laia, Barcelona, 1979.

—, La revolución de las Comunidades de Castilla (1520-1521), Siglo XXI Editores, México, 1985.

—, "Las Comunidades de Castilla. Nuevas Perspectivas", en Martínez Gil (ed.), En torno a las comunidades de Castilla: actas del Congreso Internacional "Poder, Conflicto y Revuelta en la España de Carlos I", Ediciones Universidad de Castilla-La Mancha, Toledo, 2002.

- Los Comuneros, RBA, Barcelona, 2006.

Pfandl, Ludwig, Historia de la Literatura Nacional Española en la Edad de Oro, Editorial Gili, Barcelona, 1933.

Ramos, Demetrio, Historia de las Cortes tradicionales de España, Aldecoa, Burgos, 1944.

Rivero Rodríguez, Ángel, "El mito comunero y la identidad nacional española", en Antonio Álvarez-Ossorio Alvariño y Bernardo J. García García (eds.), La Monarquía de las naciones. Patria, nación y naturaleza en la Monarquía de España, Fundación Carlos de Amberes, Madrid, 2004.

Romero Alpuente, Juan, Historia de la revolución española y otros escritos, Centro de Estudios Constitucionales, Madrid, 1989.

Rus Rufino, Salvador, Una biografía política de Fernando el Católico. La constitución de una monarquía universal, Tecnos, Madrid, 2016.

—, “QQuel Reyno no manda al Rey: y no el Rey al Reyno'. La legitimidad de Carlos I en el tiempo de las Comunidades de Castilla quinientos años después”: Res publica. Revista de Historia de las Ideas Políticas, vol. 23, n. 2 (2020), pp. 151-161.

Sánchez León, Pablo, Absolutismo y Comunidad. Los orígenes sociales de la guerra de los comuneros de Castilla, Siglo XXI Editores, Madrid, 1998.

—, "La Constitución histórica del sujeto comunero: orden absolutista y lucha por la incorporación estamental en las ciudades de Castilla, 1350-1520”, en Fernando Martínez Gil (ed.), Poder, conflicto y revuelta en la España de Carlos I, Ediciones Universidad de Castilla-La Mancha, Cuenca, 2002. 
Sáenz de Santa María Vierna, Alberto, "El testamento del Rey Católico y la legítima aragonesa”: Revista de Derecho Civil Aragonés, n. . 21-22 (2015-2016), pp. 155-172.

Sánchez González, Ramón, "La Historiografía de las Comunidades”, en Miguel F. Gómez Vozmediano (coord.), Castilla en llamas. La Mancha comunera, Almud Ediciones, Ciudad Real, 2008.

Sandoval, Prudencio de, Historia de la vida y hechos del Emperador Carlos V, máximo, fortísimo, rey católico de España y de las Indias, Islas y Tierra firma del mar Océano, ed. de Carlos Seco Serrano, Ediciones Atlas, Madrid, 1955.

Santa Cruz, Alonso de, Crónica del Emperador Carlos V, ed. de Ricardo Beltrán y Rózpide y Antonio Blázquez y Delgado-Aguiler, prólogo de Francisco de Laiglesia y Auser, Imprenta del Patronato de Huérfanos de Intendencia e Intervención Militares, Madrid, 1920-1925, cinco volúmenes.

Ternaux Compans, Henri, Les comuneros: d'après l'histoire inédite de Pedro de Alcocer, Paulin editeur, Paris, 1834.

Tierno Galván, Enrique, “¿Es el Lazarillo un libro comunero?”, en Escritos (1950-1960), Tecnos, Madrid, 1971.

—, "De las Comunidades o la historia como proceso", en Escritos (1950-1960), Tecnos, Madrid, 1971.

Valdeón Baruque, Julio, “¿La última revuelta medieval?”: Cuadernos Historia 16, n. 24, (1985), pp. 4-12.

Vázquez de Mella, Juan, Selección de elocuencia e historia, en Obras Completas, vol. I, Junta Nacional del Homenaje a Mella, Madrid, 1932. 